\title{
Redes sociales y Apoyo Social. Una aproximación a los Grupos de Autoayuda
}

\author{
Jaime Llopis Cañameras - Antropología social i cultural, UAB ${ }^{1}$
}

\section{Resumen}

En este trabajo se presenta un estado de la cuestión de la literatura sobre apoyo social y grupos de autoayuda con el objetivo de preparar el marco teórico de una investigación en curso sobre los cambios sociales y culturales de las personas que necesitan apoyo para afrontar una enfermedad crónica de sus hijos e hijas. Las redes sociales nos servirán como nuevo marco conceptual para abordar este estudio.

\begin{abstract}
This paper has the aim to provide a state-of-the-art on social support literature as a first step for developing a theoretical framework of an ongoing research about the cultural and social changes in people affected by close kin' chronical illnesses. The social networks conceptual framework will be useful as a guideline for the research.
\end{abstract}

\section{I ntroducción}

El estudio de los mecanismos de formación de las redes sociales y su dinámica es especialmente importante en el recién inaugurado siglo XXI, en el que a pesar de la creciente mercantilización e individualización de todas las esferas de la vida social, siguen surgiendo grupos o comunidades especializados en función de los intereses y las necesidades. Es lo que Barry Wellman (2001) ha llamado "individualismo conectado", es decir, comunidades flexibles que acompañan el proceso de individualización inducido por el capitalismo. Por otra parte, los sistemas de salud se enfrentan a un auge de las enfermedades crónicas, a fuertes procesos

\footnotetext{
${ }^{1}$ Enviar correspondencia a: jaimellop@yahoo.es
} 


\title{
perifèria
}

Número 3, Diciembre 2005

www. periferia. name

migratorios y a una población cada vez más anciana que ponen en evidencia la falta de recursos necesarios tanto de carácter sanitario como social. Este modelo sanitario ha ido acompañado de una reducción de los presupuestos destinados a salud y de un uso abusivo de los fármacos. En estas circunstancias, el modelo médico hegemónico pierde autoridad y progresan otros modelos alternativos.

En este contexto de reducción de recursos y búsqueda de soluciones alternativas aparece el término de "Apoyo Social" presente en disciplinas dispares como la Medicina Preventiva, la Sociología, la Psicología Comunitaria y Salud, y la Antropología. Como decíamos, la falta de recursos procedentes de la Administración favorecen la creación de entidades u organizaciones bajo la denominación de "grupos de autoayuda" o de "ayuda mutua". Estos grupos ofrecen ayuda de distinta índole a personas con el único objetivo común de satisfacer sus necesidades frente a un hecho estresante: pérdida de un ser querido, diagnóstico de una enfermedad, estigmatización social... La literatura existente sobre tales asociaciones coincide en la importancia de las redes personales de los afectados y en la necesidad de ampliarlas y reforzarlas.

De esta manera podemos observar la interrelación entre el SISTEMA SANITARIO, EL APOYO SOCIAL, LOS GRUPOS DE AUTOAYUDA y LAS REDES PERSONALES, áreas que conforman el marco teórico de esta investigación.

\section{Medicina y Antropologia}

\begin{abstract}
“Entre la historia de la medicina, la sociología de la medicina y la parte de la antropología sociomédica dedicada a los sistemas médicos no existen límites precisos. Muchos temas son analizados indistintamente por las tres disciplinas y aunque cuentan con métodos propios hay entre ellos amplia comunicación y mutua influencia. Constituyen en realidad tres vertientes del mismo estudio social de la medicina para que el que se ha utilizado en ocasiones el término de ciencia sociomédica" (Piñero, 1989: 84-85)
\end{abstract}

De esta cita se desprende la importancia que adquiere el tratar aunque sea de forma breve, la propia historia de la medicina unida a la antropología. Dicha lectura 


\section{perifèria}

Número 3, Diciembre 2005

www. periferia. name

nos ayudará a entender el entorno que ha propiciado a la aparición de los grupos de autoayuda como vehículos de apoyo social.

La existencia de la enfermedad es inherente al ser humano. En su evolución hay que destacar el hecho que con la domesticación de los animales surgieron las enfermedades infecciosas. Desde la Prehistoria, la medicina se ha caracterizado por la fuerte influencia de la religión en la interpretación de la enfermedad, como se puede observar en las culturas mesopotámicas, egipcias o en el cristianismo, por ejemplo. El Renacimiento aportará grandes avances, especialmente en el campo quirúrgico así como nacerán las teorías del contagio y de la fisiología entre otras.

El siglo XIX marca un nuevo periodo en la historia en el que la medicina también adquiere un papel importante. La revolución industrial favorece al nacimiento de las enfermedades profesionales, adoptando el médico un nuevo rol social. A mediados del siglo, la medicina se convierte en científica, aparecen las especialidades y el individuo adquiere una mayor conciencia de su estado de salud y de la propia vida. La formación del médico adquiere mayores niveles, relegando la práctica médica llevada a cabo por lo curanderos. Ante una estructuración de la medicina según la clase social, el obrero exige una atención médica frente a sus enfermedades y accidentes laborales. Dichas reivindicaciones darán paso al nacimiento de los Seguros de Enfermedad. ${ }^{2}$

En ese período histórico aparece la Antropología como disciplina. Las obras de Tylor y Morgan consolidan el evolucionismo. En este momento de desarrollo de la disciplina se caracterizó a los indígenas como seres primitivos carentes de método empírico, de aprendizaje y de experiencia hasta tal punto, que J. Frazer habla en su obra Magia y Religión de "esa hermana bastarda de la ciencia" refiriéndose a la magia aborigen (Frazer, 1911:51, citado en Comelles, J. Mạ y Martínez, A, 1993:

\footnotetext{
2 Es interesante para conocer el origen y evolución de los Seguros Sociales en España la colección formada por los tres libros siguientes editados por el Ministerio de Trabajo y Seguridad Social, y que muestran el desarrollo de los mismos desde el cambio de siglo hasta la lla República. (I) Los seguros sociales en la España del siglo XX. Orígenes y antecedentes de la Previsión Social
} 


\section{perifèria}

Número 3, Diciembre 2005

www. periferia. name

$25)^{3}$. La antropología médica surge de los estudios interculturales realizados sobre la enfermedad, la terapia, la medicina y las instituciones sanitarias. A finales del siglo XIX, la antropología juega un papel importante en el seno de la medicina. Los médicos sostenían un discurso antropológico referido a las diferencias biológicas y morales, remitiendo la discusión al rol de variables biológico/ambientales o social/político/culturales en la evolución de las especies que le servían para legitimar la lucha contra el intrusismo y para negar la posibilidad y la eficacia del autocuidado, (Menéndez ,1992 en Comelles y Martínez, 1993: 8).

El inicio del siglo XX supone la disociación aparente de la medicina y la antropología. La Salud Pública se beneficia de la Sociología y de la Antropología, mientras que la Antropología se interesa por prácticas médicas aborígenes y el rol de los curanderos. Será V. Von Weizacher (1866-1957) el primero en acuñar el término de antropología médica en 1927 - (Boixareu, 2003). Serán relevantes las obras Rivers (1924) ${ }^{5}$ y Evans Pritchard (1937). Por su parte Ackerknecht defenderá en sus obras la medicina primitiva y señala que si en el siglo anterior se observa la importancia de la Sociología en la Medicina, en este siglo XX sobresale la figura de Henry E. Sigerist (1891-1957) que apuesta por situar el carácter científico-social de la sociología y extendiéndolo al estudio de la medicina, la salud y la enfermedad en todas las sociedades y culturas.

En la década de los años cincuenta y sesenta los antropólogos se introducen en programas interdisciplinares en materia de salud. Respecto a la primera antropología médica, Good señala:

La primera antropología explícitamente "médica", el trabajo aplicado de antropólogos dedicados a la salud pública internacional en los años cincuenta

\footnotetext{
3 Frazer, J.(1911) (1965)" Magia y religión" en De Martino (ed): Magia y Civilización, Buenos Aires, Ateneo, : 49-59.

${ }^{4}$ Menendez,E.L.1992 “Grupo doméstico y proceso de salud/enfermedad/atención. Del "teoricismo" al movimiento continuo", Cuadernos Médico-Sociales (Rosario, RA)59: 3-18

${ }^{5}$ Rivers,W,H.R. (1924) Medicine, Magic and Religión, Londres, Kegan, Paul, Trench, Trubner\&Co,Ltd.
} 


\section{perifèria}

Número 3, Diciembre 2005

www. periferia. name

del siglo XX, fue formulada no sólo para realzar los esfuerzos de los profesionales de la salud pública sino como una critica de su ingenuidad cultural. Los miembros de las sociedades hacia las que iba dirigida la labor no son " recipientes vacíos " que aguardan a ser llenados con cualesquiera cocimientos sobre la salud por los que aboguen los educadores de la salud, escribió Polgar en un clásico ensayo en el que esbozaba falacias típicas de los programas de salud pública (Polgar, 1963; Cf. Paul, 19596) Sus "hábitos y creencias" constituyen elementos de un elaborado "sistema cultural" (Paul, $1955,: 15^{7}$ ) que el especialista en salud pública haría bien en comprender antes de abogar por nuevos hábitos e ideas (Good,2003:62).

Durante los años setenta nacen distintos enfoques teóricos respecto a la representación de la enfermedad y destaca la aportación realizada por Kleiman psiquiatra con formación antropológica - que asume la dualidad "Disease/Illness" pero basándose en el concepto de sistema cultural desarrollado por Geertz permitiendo el análisis de la biomedicina como cualquier sistema médico.

A partir de dicha década, se inicia la crisis del modelo médico sustentado en factores meramente biológicos ${ }^{8}$. Uno de los factores debemos buscarlo en el aspecto psicológico que sustenta la teoría de que las personas influyen en sus ambientes y viceversa, teniendo la misma importancia las variables educativas, económicas y sociales.

Finalmente el siglo XX aportó un aumento de las enfermedades degenerativas y crónicas, muchas de ellas relacionadas con los estilos de vida; un excesivo uso/abuso de fármacos y una atención médica basada en el diagnóstico de la enfermedad. Tal situación provoca el interés social que ve como la Administración

\footnotetext{
${ }^{6}$ No aparece en la bibliografía.

${ }^{7}$ Paul, B (1955) Health, Cultura and Community: Case Studies of Public Reactions to Health Programs, Rusell Sage Foundation, Nueva York.

${ }^{8}$ Para un análisis más detallado de los modelos de atención, son interesantes las aportaciones realizadas por Menéndez E.L. Dicho autor describe las siguientes formas de atención médica: (a) de tipo biomédico refiriéndose a la atención por parte de médicos para enfermedades físicas o mentales que la medicina reconoce como "enfermedades". (b) de tipo popular o tradicional, donde incluye curanderos, shamanes, etc. (c) alternativas paralelas o new age donde incluye sanadores o nuevas religiones curativas, entre otras. (d) Procedentes de otras tradiciones médicas tales como la acupuntura, medicina ayurvédica, etc. (e) Centradas en la autoayuda, tales como Alcohólicos Anónimos, o Clubes de Diabéticos entre otros.
} 


\section{perifèria}

Número 3, Diciembre 2005

www. periferia. name

está interesada en el control del gasto sanitario y una clara falta de recursos sociales, los cuales propiciarán el nacimiento de nuevas fuentes de atención bajo el concepto de "Apoyo Social" como a continuación observaremos.

\section{El Apoyo Social}

El estudio del "apoyo social" (AS), nace en las últimas décadas del pasado siglo XX y de forma especial en disciplinas como la Medicina Preventiva, la Psicología Comunitaria y de la Salud y la Sociología, aunque con anterioridad se realizaron diversos estudios, como son los estudios llevados a cabo entre otros por $E$. Durkheim, $1897^{9}$, McKenzie, $1926^{10}$ (citados en Gracia 1997:21). También es necesario señalar el desarrollo del estudio de las redes sociales por parte de la Escuela de Chicago, la cual se interesó por los problemas psicológicos y sociales derivados de la ruptura de tales redes, como veremos más adelante.

El interés por el estudio del AS nace de la importancia que adquieren las enfermedades y trastornos de connotación social, así como la relevancia que adquieren los programas de rehabilitación y tratamiento (Cohen y Syme, $1985^{11}$, en Barrón, 1996:12). También influye el elevado interés por reducir los costes provocados por el aumento de los costos en medicamentos, equipos y personal sanitario, la estandarización de técnicas quirúrgicas o de diagnóstico, o el predominio de criterios de productividad por encima de la propia calidad (Menéndez, 1984), viendo como los recursos informales son una buena solución

\footnotetext{
${ }_{9}^{9}$ Durkheim, E. (1951) Suicide: A study in Sociology. (trabajo original publicado en 1897) Glenole, III, The Fre Press.

10 McKenzie, R. (1926 “The ecological approach to the study of the human community" en R. Park y E. Burgess (comp.), The city, Chicago, Universiy of Chicago Press.

${ }^{11}$ Cohen, S y Syme, L. (1985) Social support and health, Nueva York, Academic Press.

12 Barrón, A. (1996) Apoyo social. Aspectos teóricos y aplicaciones, Siglo XXI, Madrid.
} 


\section{perifèria}

Número 3, Diciembre 2005

www. periferia. name

para conseguir dicho objetivo (Gottlieb, 1982 ${ }^{13}$ en Barrón, 1996:8). Sin embargo no debemos olvidar que cualquier persona en situación de peligro, angustia, o estrés, busca la proximidad de otra persona, sus palabras que le orienten o den consuelo, y en definitiva a cualquier aportación que le ofrezca bienestar. Como principio básico de esta necesidad es interesante la frase señalada por Sydney Cobb en los siguientes términos: “El apoyo social comienza en el útero" (Sydney Cobb. $1976^{14}$ en Fuster, 1997).

No es fácil realizar una definición exacta del concepto de "apoyo social" teniendo en cuenta la cantidad de actividades que en su término se deben incluir. Para ello será necesario distinguir tres factores fundamentales para llegar a un concepto más o menos claro del mismo. Siguiendo a autores citados por Ana Barrón (1996:11) como: Lin y al. (19865), Barrón, A (19906).

En primer lugar cabe preguntarnos por el nivel de análisis, dónde observamos el nivel comunitario, a continuación por las redes sociales y finalmente por el nivel personal. Es en el nivel comunitario en donde la sensación de pertenencia y de integración social, favorecerá destacar los roles y los distintos contextos sociales. En un segundo nivel se sitúan las redes sociales que aportan un sentido de unión con el resto de actores, y finalmente se sitúan las transacciones que se hayan presentes las relaciones más íntimas en donde se esperan intercambios recíprocos y mutuos. La existencia de relaciones sociales no implica obligatoriamente un suministro de apoyo social. Por dicha razón el término de red social se refiere a los aspectos estructurales de apoyo social, mientras que el propio concepto de apoyo social se refiere a aspectos funcionales del mismo (Barrón, 1990).

\footnotetext{
${ }^{13}$ Gottleib, B.H. (1988) Marshallling social support, Newburi Park, SAGE.

${ }^{14}$ Coob, S. (1976) “ Social support as a moderator of life stress" Psychosomatic Medecine, 38: 300-314.

15 Linn, N; Dean, A; y Ensel, W.M. (1986) Social support, life events and depression, Nueva York, Academic Press.

${ }^{16}$ Barron, A. (1990) Proyecto docente para concursar a la plaza de profesor titular del área de Psicología Social, Madrid. Departamento de Psicología Social, Universidad Complutense de Madrid.
} 


\section{perifèria}

Número 3, Diciembre 2005

www. periferia.name

Como segundo factor a tener en cuenta se sitúan las distintas perspectivas de estudio. Siguiendo a Linn y sus colaboradores (op.cit), tres son tales perspectivas. En primer lugar desde una perspectiva estructural donde se examina todo el campo social en que el sujeto está inmerso. Toma como papel fundamental el estudio de las redes sociales y sus dimensiones. Gottieb (1981) sostiene que la red social es la unidad de la estructura social que incluye todos los contactos sociales del individuo (en Barrón, 1990b). Asimismo la misma autora afirma que en un estudio de redes se obtiene información sobre sus propiedades pero no de la disponibilidad de los recursos. En segundo lugar desde una perspectiva funcional es importante distinguir entre los recursos que se intercambian en dichas transacciones y las funciones que el apoyo cumple. El énfasis se dirige a observar los aspectos cualitativos del apoyo social y en los sistemas informales de apoyo (Barrón, 1996, 1990b) y que son los siguientes: (a) Función de apoyo emocional, (b) Función de apoyo material o instrumental y (c) Función de apoyo informacional.

En tercer lugar, desde una perspectiva contextual donde siguiendo a Cohen y Syme, 1985 (citado en Barrón, 1990b) se deben tener en cuenta los aspectos siguientes:

(a) Las características de los participantes.

(b) Fuente o procedencia de apoyo.

(c) Características del receptor.

(d) El momento en que se da el apoyo.

(c) La duración de dicho apoyo.

(e) La finalidad de dicho apoyo en términos de adecuación entre el apoyo que se da y las necesidades del receptor.

De esta manera disponemos de diferentes definiciones de AS en función de la diferente persperctiva teórica. Así, mientras que Barrón (1996) lo define como: “(..) algún tipo de transacción en la que se intercambian recursos que permiten 


\section{perifèria}

Número 3, Diciembre 2005

www. periferia. name

cumplir alguna de estas funciones" refiriéndose a las funciones antes citadas, Thoits lo define como: "El grado en que las necesidades sociales básicas de la persona son satisfechas a través de la interacción con otras." (Thoits, $1982^{17}$, 1985 ${ }^{18}$ : en Barrón, A. 1996: 17-18). Finalmente cabe citar como resumen de éstas y otras definiciones, la realizada por House (1981 ${ }^{19}$, en Barrón, 1996: 18) en los siguientes términos: "transacciones interpersonales de uno o más de los siguientes tipos" y describe los siguientes: (1) Interés o apoyo emocional, (2) Ayuda o apoyo instrumental, (3) Apoyo informacional y (4) Apoyo evaluativo.

Respecto a los efectos en que el apoyo social se relaciona con la salud, y siguiendo a Cohen, 1998 (citado en Barrón, 1996:28), éstos se clasifican en:

(a) Modelos genéricos en que el apoyo social es relacionado con distintas enfermedades, bien sea por la influencia sobre patrones de conducta o por su acción sobre procesos biológicos.

(b) Modelos centrados en el estrés.

(c) Modelos de proceso psicosocial, clasificados a su vez en modelos generales de apoyo social, específicos y de especificidad del apoyo.

Tales estudios se remontan a la década de los años setenta del pasado siglo XX, y en especial en el ámbito de la salud mental. A modo de ejemplo encontramos los estudios realizados por distintos autores respecto a la falta de apoyo en que se encuentra un sujeto ante la pérdida de su cónyuge, y que conducirá a la muerte en

\footnotetext{
17 Thoits, P.A. (1982) “ Conceptual Methodological and theoretical problems in studying social support as a buffer against life stress" J ournal of Health and Social Behavior, 23,2: 145-159

18 Thoits, P.A. (1985) “Social support and psychological well-being: Theoretical posibilities” en I.G. Sarason y B.R. Sarason, Social support: Theory, research and applications, Boston, Martinus Nijhoff.

${ }^{19}$ House, J.S. (1981) Works stress and social support. Reading, M.A. Addison Wesley.
} 


\section{perifèria}

Número 3, Diciembre 2005

www.periferia.name

poco tiempo ${ }^{20}$ (Stroebe y otros, $1982^{21,}$ Rees y Lutkins, $1967^{22,}$ Krantz y otros, 198523; en Gracia, 1997: 27).

Uno de los aspectos que se observan por parte del demandante de ayuda es la circunstancia de que éste declara de forma pública su fracaso o inferioridad (Fischer y otros, 1982 ${ }^{24}$, citado en Gracia, 1997: 33), y en consecuencia su solicitud se dirigirá a personas con los que no existe competencia ni autoridad. Las redes informales están constituidas por un pluralismo de personas que intervienen en el apoyo social. Familiares, amigos o vecinos se mueven por el único objetivo de prestar ayuda, y que están movidos por que están interesados por el problema o por haberlo padecido previamente (Froland y otros, 198125, en Gracia, 1997:34).

La contribución de las redes informales al ámbito de la salud se diferencia de los sistemas formales de apoyo fundamentalmente en cinco aspectos (Gottlieb, $1983^{26}$, en Gracia, 1997: 37):

(a) Su accesibilidad natural.

(b) Su congruencia con las normas locales acerca del momento y forma en que el apoyo debe ser expresado.

(c) Sus raíces en relaciones duraderas entre iguales.

\footnotetext{
${ }^{20}$ Es lo que se denomina "efecto del corazón roto" observado cuando muere un cisne, y su pareja muere al poco tiempo, teniendo en cuenta que los cisnes viven siempre en pareja.

${ }^{21}$ Stroebe, W.; Stroewe, M.S.,Gerken, K.J y Gerken, M(1982) " The effects of bereavement on mortality: A social psychological analysis" en J.R. Eiser (comp). Social psychology and behavioural medicine, Nueva York, Wiley.

${ }^{22}$ Rees, W y Lutkins, S (1967) “Mortality of bereavement” British Medical Journal, 4: 13-16

${ }^{23}$ Krantz, D.; Grundberg, N. y BAUM, A. (1985) " Health psychology" Annual Review of Psychology, 36: 349-383

24 Fischer, J.D., Nadler,A. y Witcher-Alagna, S. (1982) "Recipients reactions to aid" Psychological Bulletin, 91: 27-54

25 Froland, C.; Pancoast, D.L.; Chapman, N.J. y Kimboko, P. (1981) “ Linking formal and informal support systems “ en B.H. Gotlieb (comp.), Social networks and social support, Londres, Sage.

${ }^{26}$ Gottlieb, B.H. (1983) Social support strategies: Guidelines for mental health practice. Londres, Sage
} 


\section{perifèria}

Número 3, Diciembre 2005

www. periferia. name

(d) Su variabilidad, comprendiendo desde la provisión de bienes y servicios materiales a la simple compañía.

(e) Su libertad e independencia de los costes económicos y psicológicos que tienen lugar cuando se utilizan los recursos profesionales.

Finalmente señalar que las fuentes de apoyo informales tienen su origen en la red personal disponiendo como vehículos formales de los mismos, los grupos de ayuda mutua y de autoayuda, como veremos más adelante (Garcia 1997: 40).

\section{Los Grupos de Autoayuda}

La idea central que subyace en el paradigma de la ayuda mutua es el hecho de que la gente que tienen problemas comunes se agrupa para proporcionarse determinados tipos de apoyo, y de esta manera afrontar de mejor forma y en grupo el problema en cuestión.

El primer texto aparecido que trata de los Grupos de Auto-Ayuda se remonta a 1902, en que Peter Kropotkin publica su libro "La ayuda mutua: un factor en evolución" (citado en Gracia, 1997) ${ }^{27}$. Los grupos de autoayuda como los conocemos hoy en día, surgen en los años treinta en Estados Unidos, siendo pionera en dicha organización la Asociación de Alcohólicos Anónimos (AAA), aunque no hay que olvidar las primeras iniciativas surgidas en Estados Unidos a principios del siglo XX, dirigidas a ayudar a los nuevos inmigrantes que deseaban instaurarse en el país (Villalba, C., 1996).

Diversos son los modelos explicativos del desarrollo y evolución constante de tales grupos, variando según los autores y citados por Gracia: la insatisfacción de las necesidades básicas o la necesidad de afiliarse (Lieberman y Borman 1976) ${ }^{28}$, su

\footnotetext{
${ }^{27}$ Kropotkin, P. (1902) Mutual aid: A factor in evolution. Londres, Heinemann.

28 Lieberman, M.A. y BORMAN, L. (1976) “Self-help and social research" Journal of Applied Bahavioral Science, 12: 265-282
} 


\section{perifèria}

Número 3, Diciembre 2005

www.periferia.name

efectividad ante las enfermedades crónicas (Gartner y Riessman (1977) ${ }^{29}$, la limitación de los servicios profesionales, el cambio de rol de la familia y vecinos (Borman 1992) ${ }^{30}$ entre otros.

La definición de "grupo de autoayuda" es difícil por la variedad de organizaciones que bajo dicho término se encuentran, así como también es necesario diferenciar el término de "Grupo de Autoayuda" de "Grupo de Ayuda Mutua". De acuerdo con Romeder ( 1933 citado en Gracia, 1997¹1)

(...) "ayuda mutua" se define como una forma especial de apoyo social, mientras que los grupos de autoayuda son grupos pequeños, autónomos y abiertos donde la principal actividad es la ayuda mutua. (...) La "ayuda mutua " es una forma de apoyo social que consiste en ayuda práctica y psicológica entre personas que comparten un mismo problema o circunstancia vital y que, por tanto, les hace relacionarse mutuamente como iguales, siendo el principal objetivo el apoyo emocional que se obtiene al compartir experiencias información y estrategias de afrontamiento.

En este sentido Menéndez define la autoayuda, desde un punto estructural, como reciprocidad, socializada primaria no satisfecha por otras relaciones (Menéndez, 1984).

Gottlieb (1988, citado en Barrón, 1986:8732), diferencia los grupos de apoyo de los grupos de autoayuda señalando que los primeros están dirigidos por un profesional, donde se combina el conocimiento experto y la experiencia. Tales grupos tienen una limitación en el tiempo y del número de sus componentes. Por otro lado los grupos de autoayuda actúan de forma autónoma, sin profesionales y sin limitación temporal. Inicialmente se puede constituir un grupo de apoyo, y al cabo de un

\footnotetext{
${ }^{29}$ Gartner ,A. y Riessman, F. (1977) Self-help in the human service. San Francisco, Jossey-Bass.

${ }^{30}$ Borman, L.B. (1992) "Self-help/mutual aid groups in stretegies for health" en Katz, A.H: Hedrick, H.L., Isenberg, D.H.,Thompson, L.H.,Goodrich, T. y Kutscher, A.H. (comp.), Self-help: Concepts and applications, Filadelfia, The Charles Press.

${ }^{31}$ Romeder, J.M. (1993) "Of surverys and definitions of self-help and mutual help", en M. Stewart y F. Lavoie (comp.), Self-help/mutual aid for seniors: Research challenges, Otawa, Self-Help Canada.

32 Gottleib, B.H. (1988) Marshalling social support. Newburi Park, SAGE.
} 


\section{perifèria}

Número 3, Diciembre 2005

www. periferia.name

tiempo puede pasar a constituirse un grupo de auto ayuda. (Taylor et al. $1988^{33}$, citado en Barrón 1996:87)

De igual forma es difícil definir las características de un grupo de autoayuda, aunque en este caso hay un mayor acuerdo. De esta manera podemos citar a Killilea, M.(1976) ${ }^{34}$,Gartner y Riessman (1977), Richardson, (1983 ${ }^{35}$ ), Rogers $\left(1987^{36}\right)$, Lieberman $(1989)^{37}$ entre otros citados por Gracia, los cuales coinciden en que las características de tales grupos son:

1. Tener una experiencia común.

2. Se demanda el apoyo y ayuda mutua.

3. Se intercambia la información.

4. Son de origen espontáneo.

5. La burocratización es un enemigo.

6. Las actividades básicas se dirigen a satisfacer las necesidades básicas de la persona, así como se llevan a cabo actividades como grupos de presión ante la sociedad.

7. Existe reciprocidad.

8. Se facilita la reestructuración cognitiva de los individuos.

\footnotetext{
33 Taylor, S.E., Falke, L., Mazel, R.M. y Hilsberg, B.L. (1988) "Sources os satisfaction and dissatisfaction among members of cancer support groups" en B. Gottlieb, Marshalling social support, Newbury Park, SAGE.

${ }^{34}$ Killilea, M. (1976) "Mutual help organizations: Interpretations of the literatura" en G. Kaplan y M. Killilea. (comp.), Support systems and mutual help: Multidisciplinary explorations, Nueva York, Grune\&Satratton.

${ }^{35}$ Richardson, A (1983) “The diversity of self-help groups" en S. Hatch y I. Kickbush (comp.), Self-help and health in Europe: New approaches in health care, Copenhagen, World Health Organization.

${ }^{36}$ Rogers, C. (1987) Mutual aid as a mechanism for health promotion and disease prevention, Toronto, Health and Welfare Canada.

37 Lieberman, M.A. (1989) “Mutual-aid groups: An underutilizedresource among the elderly" en T.J. Powell (comp.), Annual review of geriatrics and gerontology. Nueva York, Springer.
} 


\section{perifèria}

Número 3, Diciembre 2005

www.periferia.name

9. Las interacciones se realizan "cara a cara".

Finalmente es importante señalar el amplio abanico de intervención en la que puede actuar un grupo de ayuda mutua ${ }^{38}$ :

1. Programas de apoyo a la familia.

2. Programas de apoyo a la tercera edad.

3. Programas de apoyo a enfermos mentales.

4. Programa de apoyo frente a adicciones, discapacidades y drogodependencias.

5. Programas de apoyo frente a enfermedades que amanzana la propia vida del afectado.

6. Programas de apoyo frente a enfermedades crónicas.

Sería un error olvidarnos de las nuevas tecnologías, las cuales han irrumpido en el campo social. Es el caso de los Grupos de Autoayuda on-line. Al respecto existen diversos estudios, como es el caso del llevado a cabo con cuidadores y enfermos afectados por la enfermedad de Alzheimer (Maya, 2001). A través de la informática se ahorra tiempo, disminuyen los costos de desplazamiento y se salvan las limitaciones físicas, aunque se pierde la riqueza de la comunicación cara a cara.

\footnotetext{
${ }^{38}$ Quiero agradecer los consejos que en los inicios de mi investigación, me proporcionó el Dr. Josep Canals Sala, el cual me facilitó su tesis doctoral "El regreso de la reciprocidad - Grupos de ayuda mutua y asociaciones de personas afectadas en la crisis del Estado del Bienestar "Tarragona, julio 2002, en la que presenta un exhaustivo análisis de los Grupos de Ayuda Mutua.
} 


\section{perifèria}

Número 3, Diciembre 2005

www.periferia.name

\section{Las Redes Sociales}

Un buen punto de partida es la afirmación de Wellman (2000) según la cual el mundo está compuesto de redes, no por grupos. Félix Requena define "red social" como:

“una serie de vínculos entre un conjunto definido de actores sociales. Las características de estos vínculos como un todo tienen la propiedad de proporcionar interpretaciones de la conducta social de los actores implicados en la red."(Requena, 1989).

A esta definición debemos añadir que detrás de la relación, hay motivaciones e intereses que de forma racional los actores actúan para satisfacerlos (Degenne y Forsé $^{39}$ en De Federico, 1999)

Tres líneas son básicas en el desarrollo del estudio de las redes sociales. En primer lugar la Sociometría, en segundo lugar los estudios llevados a cabo en la Escuela de Manchester y los Ilamados Estudios de Comunidad.

La Sociometría es un método para el estudio de las relaciones interpersonales de afinidad en los pequeños grupos, desarrollado ampliamente por Jacob Moreno (1934 ${ }^{40}$ citado en Pizarro, N.1998). Esta línea fue continuada por investigadores de Harvard y Chicago, entre los que destaca el antropólogo W. Lloyd Warner, que colaboró en las investigaciones que llevaba a cabo Elton Mayo en la Western Electric Company de Chicago.

En la Escuela de Manchester son importantes las aportaciones de Max Gluckman, Clyde Mitchell, J. Barnes o Victor Turner, entre otros. Será precisamente John Barnes (1954) ${ }^{41}$, quien por primera vez utilizará el término de red (network) en su

\footnotetext{
39 Degenne, A. y Forsé, A. (1994) Les réseaux sociaux : una analyse structurale en sociologie. París, Armand Colin.

${ }^{40}$ Moreno, J.L. (1934) Who shall survive. Washington D.C.., Nervous and Mental Disease Monograph, no 58.

${ }^{41}$ Barnes, J.A (1954) "Class and comités in a Norwegian Islan Parish" Human Relations, vol7, no 1: 3958
} 


\section{perifèria}

Número 3, Diciembre 2005

www. periferia. name

estudio llevado a cabo en una pequeña aldea de pescadores en Noruega (Molina, 2001, Wellman, 2000). Más tarde Elisabeth Bott (1955) ${ }^{42}$ publicará su estudio donde demuestra que la separación de los roles conyugales de los matrimonios urbanos londinenses eran una función de la red social de la pareja.

Finalmente, a partir de los años 70 se desarrollan en Estados Unidos y Canadá un conjunto de estudios centrados en el redescubrimiento de la "comunidad" en los barrios de las ciudades americanas. Barry Wellman, uno de los investigadores más importantes de esta corriente funda en 1978 la Asociación Internacional para el Análisis de Redes (INSNA) apareciendo a partir de entonces diversas publicaciones impulsadas por la propia asociación.

El análisis de las redes sociales (Requena, F. 2003) investiga (a) el efecto de la posición de la red del actor en su conducta, (b) La identificación de los subgrupos en la estructura o la red, y (c) la naturaleza de las relaciones entre los actores. Las aplicaciones posibles derivadas de esta perspectiva son múltiples: estudios sociológicos de la organización (Ross, C. $\left(1987^{43}\right)$, la sociología de la familia (Milardo $\left(1988^{44}\right)$, la integración local de los barrios urbanos (Fischer, 1982 ${ }^{45}$ ), la influencia de la red social en la salud mental de la población anciana (La Huerta et al., 2004), la búsqueda de trabajo por parte del inmigrante (Arjona et al., 2005), este último en la misma línea de la investigación llevada a cabo por Adler Lommitz (1994) en que ponía de manifiesto las formas de subsistir las familias de un barrio de México, a los que denominaba "huérfanos de protección social".

\footnotetext{
42 Bott, E.(1955) Family and social network. La traducción revisada al castellano corresponde a la de 1990 con el título Familia y Red social, Taurus Alfaguara, Madrid.

${ }^{43}$ Ross, C. (1987) “ Organizational dimensions of metropolitan dominance: Prominence in the netwok of corporate control, 1955 - 1975", en American Sociological Review, vol. 52 : 258-267

${ }^{44}$ Milardo, R. (1988) Familias and social networks, Beverly Hills (Calif.) Sage.

45 Fischer, C.S. (1982) To dwell among friends: Personal networks in town and city, Chicago, Chicago University Press.
} 


\section{perifèria}

Número 3, Diciembre 2005

www. periferia. name

A estos estudios debemos añadir aquellos que están ligados a los Grupos de Autoayuda, siendo necesario recordar que la filosofía de muchos de tales grupos manifiesta la necesidad de ampliar o reforzar las redes personales de los afectados, especialmente cuando se tratan aspectos de la salud. A modo de ejemplo, destacamos los que ponen de manifiesto el incumplimiento de los tratamientos terapéuticos por parte de los usuarios (Urraca, 199046), o la influencia que ejerce el apoyo social en pacientes con hipertensión arterial (Menéndez et.al, 2003 ${ }^{47}$ )

\section{La investigación en curso}

La investigación en curso está enmarcada dentro del programa de Doctorado en Antropología Social y Cultural de la Universidad Autónoma de Barcelona. La investigación se inició en el mes de septiembre de 2004 y pretende dar a conocer la importancia del estudio de las redes personales en el ámbito de la salud, partiendo de la pregunta inicial ¿cómo y por qué se asocian los padres de niños afectados por una enfermedad crónica?, de la que se derivan entre otras preguntas la siguiente: ¿se modifican las redes personales de aquellos padres a cuyos hijos o hijas se les diagnostica una enfermedad crónica?

Para ello ha sido necesaria la revisión bibliografía de los temas que el presente artículo se presenta y que configuran parte del marco conceptual de la investigación. Al mismo tiempo se está llevando la observación de campo en dos Asociaciones cuyo grupo de usuarios son padres y madres de niños/as afectado/as por dos enfermedades de carácter crónico.

En primer lugar y durante nueve meses - octubre 2004 a junio 2005 - dicha observación se ha llevado a cabo en la Associació de Celíacs de Catalunya con sede

\footnotetext{
${ }^{46}$ Urraca, S. (1990) “El apoyo social en la salud y la enfermedad” Jano, 9-15, marzo, Vol, XXXVIII № 898: 53

47 Menéndez, C, Montes, A., Gamarra, T. y otros (2003) “Influencia del apoyo social en pacientes con hipertensión arterial”. Atención Primaria, 31 (8) : 506-513
} 


\section{perifèria}

Número 3, Diciembre 2005

www. periferia.name

en Barcelona. Esta Asociación fue fundada en 1977, siendo pionera en su género en España. Su principal objetivo se dirige a mejorar la calidad de vida del enfermo celíaco ${ }^{48}$.

En junio de 2005, la Asociación contaba con más de cinco mil socios. La atención a los mismos se realiza a través del correo electrónico, telefónicamente o entrevista personal, esta última a cargo de personal voluntario que coexiste con personal asalariado. Entre los servicios ofertados por la Asociación, destaca la información sobre aspectos dietéticos, la publicación de una guía de alimentos permitidos, la organización de charlas y conferencias, así como colonias de verano para niños y niñas con la enfermedad celíaca.

La observación llevada a cabo, ha consistido en la presencia en las entrevistas llevadas a cabo las voluntarias y los afectados. Uno de los principales problemas detectados en dicho periodo a los que se enfrenta el enfermo celíaco o sus familiares, consisten en la falta de información respecto a la enfermedad, el desconocimiento de la composición de los alimentos, la dificultad de adquirirlos en establecimientos habituales y el elevado coste de los productos.

En segundo lugar, y desde octubre de 2005 y hasta la fecha, la observación se está llevando a cabo en la Associació d'Ajuda de Cardiopatías Infantils ${ }^{49}$ de Catalunya AACIC - con sede en Barcelona.

Dicha Asociación y como su nombre indica se orienta a mejorar la calidad de vida de los niños que padecen una enfermedad cardiaca en su nacimiento. AACIC se

\footnotetext{
48 La enfermedad celíaca (EC), y siguiendo la definición realizada por la Sociedad Europea de Gastroenterología y Nutrición Pediátrica - ESPGAN; consiste en la anormal intolerancia al gluten que condiciona, en individuos genéticamente predispuestos, una lesión severa de la mucosa del intestino delgado superior. El gluten es una proteína presente en el trigo, cebada, centeno y cebada, por lo que son alimentos completamente prohibidos en el enfermo celíaco. Su prevalencia se sitúa en el $1 \times 300$ niños nacidos en España.

${ }^{49}$ Se considera cardiopatía congénita a toda malformación del corazón y/o de sus vasos presentes en el mismo momento de nacer. Su prevalencia se sitúa entre un 6 y un 10 por 100 niños nacidos en Catalunya.
} 


\section{perifèria}

Número 3, Diciembre 2005

www. periferia. name

fundó en 1994, siendo pionera en España como entidad preocupada por las enfermedades congénitas. En la actualidad cuenta con aproximadamente 250 asociados. Presenta distintos proyectos basados en las necesidades detectadas a lo largo de los años de su fundación. Entre tales proyectos, merece especial atención los servicios de soporte psicosocial y de orientación dirigido a niños, adolescentes y jóvenes, así como a sus familiares, que se lleva a cabo a través de entrevistas personales y la organización de distintos Grupos de Ayuda Mutua. También cuentan entre sus proyectos la labor de asesoramiento y formación a los profesionales que de alguna forma forman parte del entorno social y educativo de los afectados; así como un extenso programa de formación al voluntariado y apoyo a la investigación en materia de enfermedades cardíacas infantiles. Al frente de tales proyectos la Asociación cuenta con profesionales que conforman un equipo multidisciplinar: Trabajadora Social, Psicopedagoga y psicólogas.

Ambas asociaciones presentan una concepción de la enfermedad diferente que viene dada por el riesgo existente de muerte. Mientras que en el primer caso la enfermedad celíaca o intolerancia al gluten comporta una dieta estricta de dicha enzima, pero a priori no hay un riesgo importante, en el caso de las cardiopatías congénitas las personas afectadas se ven sometidas a largos periodos de ingresos hospitalarios y frecuentes intervenciones quirúrgicas con el riesgo que ello comporta.

Como segunda técnica empleada en esta primera fase de la investigación se ha realizado una encuesta dirigida a conocer el perfil de las familias asociadas a las Asociaciones en estudio, así como conocer las demandas y angustias de tales familias. Por dicho motivo y coincidiendo con el Día Internacional de la Enfermedad Celíaca (21 de mayo de 2005), llevamos a cabo una encuesta entre las familias asistentes a dicha celebración que tuvo lugar en Barcelona. La participación de contestación al cuestionario presentado fue de 75 padres/madres de niños y niñas afectados/as por la enfermedad celíaca. Sobre dicha muestra de una población de 555 personas (según datos facilitados por la propia Asociación), y tras el 


\section{perifèria}

Número 3, Diciembre 2005

www. periferia.name

correspondiente análisis estadístico mediante SPSS, se obtiene entre otros datos que se tarda una semana en acudir a la Asociación tras haber sido diagnosticada la enfermedad $(53,3 \%)$, la demanda solicitada se dirige mayoritariamente a recabar información sobre aspectos diversos (64\%). Por otra parte, destaca la diferencia existente entre los temores y las angustias que refieren en razón de género los participantes. Mientras los padres manifiestan una mayor preocupación por las futuras relaciones de sus hijos/as, las madres declaran una mayor preocupación por los cambios en los hábitos alimenticios.

En relación a la segunda Asociación - AACIC - en el momento de redactar el presente artículo se está negociando la posibilidad de enviar el mismo cuestionario por correo a todas las familias con hijos/as afectados por una enfermedad cardiaca congénita y asociadas a la Asociación. De esta manera se podría comparar los resultados obtenidos, en especial los perfiles de los usuarios de ambas Asociaciones, así como detectar las angustias y temores respecto a cada una de las enfermedades en estudio.

Finalmente se está llevando a cabo un estudio de las redes personales de padres o madres de niños/as afectados por la enfermedad celíaca y por alguna cardiopatía congénita. La muestra, aunque pequeña, procede de la propia observación en ambas Asociaciones y cuyas personas candidatas estén interesadas en participar en la investigación.

Para dicha investigación se establece un estudio longitudinal durante seis meses en los que se observan las posibles modificaciones de las relaciones personales de las personas participantes, y se utiliza como programa específico para el análisis de redes personales, el denominado Egonet ${ }^{50}$. Las personas participantes deben residir en la ciudad de Barcelona y/o en la población de L'Hospitalet del Llobregat. Esta

\footnotetext{
${ }^{50}$ http://www. mdlogix.com/egonet.htm [consulta: 1-12-05].
} 


\section{perifèria}

Número 3, Diciembre 2005

www.periferia.name

delimitación viene dada por un problema básicamente presupuestario del propio investigador.

Con las preguntas que se realizan a las personas colaboradoras, se obtiene un perfil de dicha persona, su red de relaciones personales. Los tipos de ayuda que estaría dispuesta a solicitar a cada una de las personas citadas por ella, y las relaciones existentes entre las personas citadas (alteri). Al mismo tiempo y tras comparar la red personal al cabo de seis meses (tiempo previsto para la segunda entrevista), se observa las modificaciones que puedan surgir desde que fue diagnosticada la enfermedad en su hijo o hija, por lo que como requisito fundamental para poder realizar el estudio de redes personales, es que no haya trascurrido más de un año desde el diagnóstico de la enfermedad.

Al mismo tiempo con el estudio de tales redes personales, podremos observar el papel que las Asociaciones en estudio llevan a cabo en la modificación de tales redes personales.

A nivel de un análisis cuantitativo de los datos obtenidos se analizarán a través del correspondiente paquete estadístico SPSS, así como del propio programa de análisis de las relaciones personales realizado a través del programa Egonet. Por el contrario el análisis cualitativo de la información se extraerá del propio Diario de Campo realizado desde el inicio de la investigación.

Finalmente es necesario señalar que tras las conclusiones que resulten de la investigación en curso, se iniciará una nueva etapa dirigida a la realización de la tesis correspondiente para la obtención del titulo de Doctorado en esta disciplina.

\section{Bibliografía}

Ackerknecht, E.H. (1985). Medicina y antropología Social. Madrid: Akal.

Adler Lomnitz, L. (1994). Redes sociales, cultura y poder. Ensayos de Antropología Latinoamericana. México D.F : Facultad Latinoamericana de Ciencias Sociales.

Arjona, A. y Checa, J.C. (2005). “ Movilización de recursos del empresariado étnico 


\section{perifèria}

Número 3, Diciembre 2005

www. periferia.name

en Almería: la importancia de las redes sociales." Revista Redes, Vol. 8\#3, agosto. http://revista_redes.rediris.es

Barrón, A. (1990ạ). “ Apoyo social: Definición.” Jano 9-15, vol. XXXVIII - no 898: 62-73

Barrón, A. (1990b). "Perspectivas de estudio en el apoyo social." Jano 9-15, vol. XXXVIII - no 898: 74-85

- (1996). Apoyo social. Aspectos teóricos y aplicaciones. Madrid: Siglo XXI.

Boixareu, R. Mà.(coord.). (2003). De l'Antropología Filosófica a l'Antropología de la Salud. Barcelona: Cátedra Ramón Llull Blanquerna.

Bott, E. (1990). Familia y red social. Madrid, Taurus Alfaguara.

Comelles, J.Mạ. y Martínez, A. (1993). Enfermedad, cultura y sociedad. Madrid: Eudema-Antropología Horizontes.

De Federico, A. (1999). "Resención de Felix Requena Santos - Redes sociales y cuestionarios." Papers. Revista de Sociología (58): 191-201

Evans Pritchard, E.E. (1997). Brujería, magia y oráculos entre los azande. Barcelona: Anagrama.

Good, B. (2003). Medicina, racionalidad y experiencia. Una perspectiva antropológica. Barcelona, Ediciones Bellaterra.

Gracia, E. (1997). El apoyo social en la intervención comunitaria. Barcelona: Paidós.

La Huerta, C., Borell, C., Rodríguez, M. Pérez, K. y Nebot, M. (2004) “La influencia de la red social en la salud mental de la población anciana." Gaceta Sanitaria.18 (2): 83-91

Laín, P. (1989): Historia de la medicina. Barcelona: Salvat Editores.

López Piñero, J. Mạ . (1990). Historia de la medicina. Madrid: Historia 16. 


\section{perifèria}

Número 3, Diciembre 2005

www. periferia.name

Maya, I. (2001). "Aspectos psicosociales de un grupo de autoayuda on-line de cuidadores y enfermos de Alzheimer." (título original: "Psycho-social aspects in an on-line self-groups of Alzheimer's patients and caregivers. " en F. Casas y Saurina, C. (Ed.) : Procedings of the Third Conference of the International Society for Quality of Life Studies: 923-936.

Menéndez, E.L. (1984). Hacia una práctica médica alternativa. Hegemonia y autoatención (gestión) en salud. México D.F.: Cuadernos de la Casa Chata, oㅡ 86. Centro de Investigaciones y Estudios Superiores en Antropología Social.

- (2003). “Modelos de atención de los padecimientos de exclusiones teóricas y articulaciones prácticas." Ciencia and Saúde colectiva, vol. 8, no 1: 185207.

Menéndez, C., Montes, A., Gamarra, T., Núñez, C., Alonso, A.,Bujuan, S. (2003). "Influencia del apoyo social en pacientes con hipertensión arterial esencial." Atención Primaria, 31 (8): 506-513.

Molina, J. L. (2001). El análisis de redes sociales. Una aproximación. Barcelona: Ediciones Bellaterra.

Osorio, R. Má. (2001). Entender y atender la enfermedad Los saberes maternos frente a los padecimientos infantiles. México: Ciesas, INAH.

Pizarro, N. (1988). "Capítulo VI. Tipología y dinámica de las estructuras sociales" en Tratado de metodología de las Ciencias Sociales. Madrid: Siglo XXI: 327-409.

Porter, R. (2003). Breve historia de la medicina. De la antigüedad hasta nuestros días. Madrid: Taurus Minor.

Requena, F. (1989)."El concepto de red social." REIS-Revista Española de Investigaciones Sociológicas, (48), octubre/diciembre: 137-152.

-(2003). Análisis de redes sociales. Orígenes, teorías y aplicaciones. Madrid : Centro de Investigaciones Sociales-C.I.S. 


\section{perifèria}

Número 3, Diciembre 2005

www.periferia.name

Urraca, S. (1990) “El apoyo social en la salud y la enfermedad." Jano, 9-15, vol. XXXVIII - no 898: 53.

Villalba, C. (1996). “Los grupos de apoyo basados en la autoayuda : una propuesta para el inicio y acompañamiento profesional." Intervención Psicosocial, vol. V - № 15: 23-41.

Wellman, B. (2000). “El análisis estructural : del método y la metáfora a la teoría y la sustancia", Política y Sociedad (33): 11-40.

- (2001). "Physical Place and CyberPlace: The Rise of Personalized Networking" en Blokland, Talja \& Mike Savage, eds., "Networks, Class and Place", número especial del International Journal of Urban and Regional Research, 25(2), June (227-252). 